\title{
Ethanol extract of Lithospermum erythrorhizon Sieb. et Zucc. promotes osteoblastogenesis through the regulation of Runx 2 and Osterix
}

\author{
YOU HEE CHOI ${ }^{*}$, GEUM SOOG KIM ${ }^{2 *}$, JAE HO CHOI ${ }^{3}$, SUN WOO JIN ${ }^{3}$, HYUNG GYUN KIM $^{3}$, \\ YOUNHO HAN ${ }^{1}$, DAE YOUNG LEE ${ }^{2}$, SOO IM CHOI ${ }^{4}$, SEUNG YU KIM ${ }^{2}$, \\ YOUNG SUP AHN ${ }^{2}$, KWANG YOUL LEE $^{1}$ and HYE GWANG JEONG ${ }^{3}$ \\ ${ }^{1}$ College of Pharmacy, Chonnam National University, Gwangju 500-757; ${ }^{2}$ Department of Herbal Crop Research, National \\ Institute of Horticultural and Herbal Science, RDA, Eumseong 369-873; ${ }^{3}$ College of Pharmacy, \\ Chungnam National University, Daejeon 305-764; ${ }^{4}$ YD Global Life Science Co., Ltd., \\ Seongnam 462-807, Republic of Korea
}

Received November 17, 2015; Accepted June 16, 2016

DOI: $10.3892 /$ ijmm.2016.2655

\begin{abstract}
Bone remodeling and homeostasis are largely the result of the coordinated action of osteoblasts and osteoclasts. Osteoblasts are responsible for bone formation. The differentiation of osteoblasts is regulated by the transcription factors, Runx2 and Osterix. Natural products of plant origin are still a major part of traditional medicinal systems in Korea. The root of Lithospermum erythrorhizon Sieb. et Zucc. (LR), the purple gromwell, is an herbal medicine used for inflammatory and infectious diseases. LR is an anti-inflammatory and exerts anticancer effects by inducing the apoptosis of cancer cells. However, the precise molecular signaling mechanisms of osteoblastogenesis as regards LR and osteoblast transcription are not yet known. In this study, we investigated the effects of ethanol $(\mathrm{EtOH})$ extract of LR (LES) on the osteoblast differentiation of $\mathrm{C} 2 \mathrm{C} 12$ myoblasts induced by bone morphogenetic protein 4 (BMP4) and the potential involvement of Runx2 and Osterix in these effects. We found that the LES exhibited an ability to induce osteoblast differentiation. LES increased the expression of the osteoblast marker, alkaline phosphatase (ALP), as well as its activity, as shown by ALP staining
\end{abstract}

Correspondence to: Professor Hye Gwang Jeong, College of Pharmacy, Chungnam National University, 220 Gung-dong, Daejeon 305-764, Republic of Korea

E-mail: hgjeong@cnu.ac.kr

Professor Kwang Youl Lee, College of Pharmacy, Chonnam National University, 300 Yongbong-dong, Gwangju 500-757, Republic of Korea E-mail: kwanglee@jnu.ac.kr

${ }^{*}$ Contributed equally

Key words: Lithospermum erythrorhizon, Runx2, Osterix, osteoblast differentiation and ALP activity assay. LES also increased mineralization, as shown by Alizarin Red S staining. Treatment with LES increased the protein levels (as shown by immunoblotting), as well as the transcriptional activity of Runx 2 and Osterix and enhanced osteogenic activity. These results suggest that LES modulates osteoblast differentiation at least in part through Runx 2 and Osterix.

\section{Introduction}

Bone is actively maintained by the coordinated balance between osteoblasts and osteoclasts (1-3). Osteoblasts mediate bone formation, while osteoclasts are responsible for bone resorption $(1,2)$. The activities of osteoblasts can be regulated at the level of differentiation by various regulatory signals. The differentiation and activity of osteoblasts are regulated by various anabolic factors, such as insulin, members of the transforming growth factor (TGF) $\beta$ family [including bone morphogenetic proteins (BMPs)] and Wnt proteins, and by intracellular kinases, such as Akt (4). In particular, BMPs initiate osteoblast differentiation through the induction of the expression and post-translational modification of various osteogenic transcription factors, including Runx2 (Cbfa1), Osterix and several homeodomain-containing Dlx proteins (5-10). Subsequently, these osteogenic transcription factors regulate the differentiation of osteoblasts (10-16).

The Runt domain transcription factors are composed of a larger DNA-binding $\alpha$ subunit and a smaller non-DNA-binding $\beta$ subunit. There are three mammalian genes (Runx1, Runx2, and Runx3) encoding the $\alpha$ subunit. Runx 2 and Runx 3 are essential for chondrocyte maturation, a prerequisite for endochondral ossification. In addition, Runx 2 is essential for the commitment of multipotent mesenchymal cells into the osteoblastic lineage, and it inhibits adipocyte differentiation (17). Runx2 DNA binding sequences have been identified in the enhancer/promoter regions of many osteoblast specific genes, and Runx 2 can bind to the osteoblast-specific cis-acting element (OSE) present in the promoter regions of collagen type I, 
$\alpha 1$ (COL1A1), osteocalcin $(O C)$, alkaline phosphatase $(A L P)$, bone sialoprotein $(B S P)$ and osteopontin $(O P N)(18,19)$. The function of Runx2 is regulated by osteogenic signaling factors, such as BMP2, a member of the TGF- $\beta$ superfamily (20). BMP2 induces Runx2 expression through Smad1/5/8, and BMP2-activated Smads physically interact with Runx2 to induce osteoblast differentiation (7,21-23).

Osterix (also known as $\mathrm{Sp} 7$ ) is a zinc finger-containing osteoblast-specific transcription factor and it is essential for the differentiation and proliferation of osteoblasts (24-27). The DNA-binding domain of Osterix is located at the C-terminus and it contains three $\mathrm{C} 2 \mathrm{H} 2$-type zinc finger domains that share a high degree of identity with similar motives in Sp1, $\mathrm{Sp} 3$ and Sp4. N-terminal proline-rich region (PRR) mediates the protein-protein interaction. Osterix acts downstream of Runx2 and regulates the expression of many osteoblast differentiation markers including ALP, OC, osteonectin, OPN and Runx2 $(15,24,28)$.

Bone mass in adult humans decreases with age, leading to an increased risk of fractures. Bone mineral density (BMD) and bone metabolism are affected by genetic, endocrine, mechanical and nutritional factors, with interactions among the different factors (29). Nutritional factors are particularly important for bone health as they are modifiable (30). Natural products of plant origin are still a major part of traditional medicinal systems in Korea.

The root of Lithospermum erythrorhizon Sieb.etZucc.(LR), an herbal medicine, is known to possess various antiviral and biological activities, including the inhibition of human immunodeficiency virus type 1 (HIV-1), and it is extensively used in traditional medicine due to the known functions of herbs described in the literature of traditional Korean and Chinese medicines $(31,32)$. Ethanol $(\mathrm{EtOH})$ extract from LR (LES) has long been used in traditional Asian medicine for the treatment of skin cancer. It has been reported that the extracts from LR attenuates immunosuppression induced by cyclophosphamide, an antitumor agent $(33,34)$. The majority of studies on the bioactivities of LR have been carried out mainly with naphthoquinone pigments, including shikonin and its derivatives, which are extracted using non-polar solvents, such as hexane or by supercritical extraction $(35,36)$. Shikonin, a major active component of LR, possesses numerous pharmacological properties, including anti-inflammatory properties. Shikonin plays a dual role in the regulation of the early and late stages of collagen type II arthritis (37). Shikonin exerts protective effects on cartilage in rheumatoid arthritis (38), but also induces osteoclast differentiation in vitro (39). However, the function of LR in osteoblast differentiation remains unknown. Moreover, to the best of our knowledge, there are only a few studies available to date on the bioactivities of water-soluble and EtOH extracts of LR, even though they are more suitable materials for the development of health functional food from LR.

In this study, we examined the effects of LES on osteoblastogenesis and we aimed to determine whether the osteoblast transcription factors, Runx 2 and Osterix, play a role in these effects. We demonstrated that treatment with LES promoted osteoblast differentiation induced by BMP4 and enhanced the osteogenic functions of Runx 2 and Osterix by increasing their protein levels and transcriptional activity.

\section{Materials and methods}

Plant materials and extraction. Dried 1-year-old Lithospermi radix (LR) was purchased from Jacheon, Chungbuk, South Korea. A voucher specimen (MPS000071) has been deposited at the Herbarium of the Department of Herbal Crop Research, National Institute of Horticultural and Herbal Science, RDA, Eumseong, Korea. The powder of LR $(1.5 \mathrm{~kg})$ was extracted with $70 \% \mathrm{EtOH}(15 \mathrm{l})$ at $80^{\circ} \mathrm{C}$ for $2.5 \mathrm{~h}$ using a natural substance extractor (EG-BE1; TIPBio, Siheung, Korea) to obtain $70 \% \mathrm{EtOH}$ extract. The EtOH extract was concentrated under a vacuum using a rotary evaporator (N-1200B; Eyela, Tokyo, Japan) and dried in a freeze dryer (LP20; ilShinBioBase Co.,Ltd., Dongducheon, Korea) to yield the final test samples (LES, $424 \mathrm{~g}$ ).

Plasmids, antibodies and reagents. Plasmids for Myc-tagged Osterix and Myc-tagged Runx2 were constructed in a CMV promoter-derived mammalian expression vector (pCS4-3Myc; obtained from Dr C.Y. Yeo, Ehwa University, Korea). Anti-Myc (no.9E10, diluted 1:1,000) was purchased from Roche Applied Science (Seokyung Bldg. Seoul, Korea). Anti- $\alpha$-tubulin antibody (no. B-5-1-2, diluted 1:5,000) was purchased from Sigma-Aldrich (St. Louis, MO, USA). Anti-Osterix (no. A-13, diluted 1:1,000) and Dlx5 antibodies (no. C-20, diluted 1:1,000) were purchased from Santa Cruz Biotechnology, Inc. (Dallas, TX, USA). Anti-Runx2 antibody (no. ab76956, diluted 1:1,000) was purchased from Abcam (Boston, MA, USA). Recombinant human BMP4 was purchased from R\&D Systems (Minneapolis, MN, USA).

Cell culture and transient transfection. The cells (293 cells and $\mathrm{C} 2 \mathrm{C} 12$ mouse myoblasts) were cultured at $37^{\circ} \mathrm{C}, 5 \% \mathrm{CO}_{2}$ in Dulbecco's modified Eagle's medium (DMEM) supplemented with 5\% (for 293 cells) or $10 \%$ (for $\mathrm{C} 2 \mathrm{C} 12$ cells) fetal bovine serum (FBS), $100 \mathrm{U} / \mathrm{ml}$ penicillin, and $100 \mathrm{~g} / \mathrm{ml}$ streptomycin. All cells were purchased from the American Type Culture Collection (ATCC, Manassas, VA, USA). The C2C12 cells were treated with BMP4 $(30 \mathrm{ng} / \mathrm{ml})$ and the EtOH extract from Lithospermum erythrorhizon Sieb. et Zicao (LES) (each 30 or $60 \mathrm{mg} / \mathrm{ml}$ ) for 3 days. DMEM, FBS, and the antibiotics were purchased from Life Technologies (Grand Island, NY, USA). Transient transfection was performed using a polyethylenimine (PEI) (Polysciences, Inc., Warrington, PA, USA)-mediated method. Total amounts of transfected plasmids in each group were equalized by adding the empty vector (pCS4+; obtained from Dr Yeo CY).

Cell lysate preparation and immunoblot analysis. The cells were lysed in ice-cold lysis buffer [25 mM HEPES (pH 7.5), $150 \mathrm{mM} \mathrm{NaCl}, 1 \% \mathrm{NP}-40,0.25 \%$ sodium deoxycholate, $10 \%$ glycerol, $1 \mathrm{mM}$ EDTA] containing phosphatase inhibitors $\left(25 \mathrm{mM} \mathrm{NaF}, 1 \mathrm{mM} \mathrm{Na} \mathrm{VO}_{4}\right)$ and protease inhibitors $(250 \mu \mathrm{M}$ phenylmethylsulfonyl fluoride, $10 \mu \mathrm{g} / \mathrm{ml}$ leupeptin, $10 \mu \mathrm{g} / \mathrm{ml}$ aprotinin, and $10 \mu \mathrm{g} / \mathrm{ml}$ pepstatin A). Lysates were cleared by centrifugation at $16,000 \mathrm{xg}$ for $15 \mathrm{~min}$ at $4^{\circ} \mathrm{C}$, and the supernatants were used as cell lysates. Cell lysates containing $30 \mu \mathrm{g}$ of total proteins were subjected to sodium dodecyl sulfate-polyacrylamide gel electrophoresis (SDS-PAGE) and the protein content was estimated using a bovine serum albumin protein assay. Proteins were mixed with sample buffer containing 
$\beta$-mercaptoethanol and heated at $100^{\circ} \mathrm{C}$ for $3 \mathrm{~min}$. A total of $30 \mu \mathrm{g}$ of each cell lysate was fractionated by SDS-PAGE on a $10 \%$ polyacrylamide gel and transferred onto polyvinylidene difluoride (PVDF) membranes. After blocking with 5\% skim milk in Tris-buffered saline (TBS) containing 0.02\% Tween-20 at room temperature for $40 \mathrm{~min}$, the proteins were visualized with appropriate primary antibodies (diluted 1:1,000) at room temperature for $1 \mathrm{~h}$. Tubulin (diluted 1:5,000) was used as a loading control. This was followed by the addition of antirabbit or anti-mouse horseradish peroxidase (HRP)-conjugated secondary antibodies diluted 1:25,000 in TBS/Tween-20. The blots were visualized by enhanced ECL-chemiluminescence reagent (GE Healthcare Life Sciences, Logan, UT, USA). Signals were detected and analyzed using the LAS-4000 luminescent image analyzer (Fuji Photo Film Co., Ltd., Tokyo, Japan).

Luciferase reporter assay. The $\mathrm{C} 2 \mathrm{C} 12$ cells were seeded on 24-well plates 1 day prior to transfection. ALP-Luc (obtained from H.M. Ryoo, Seoul University, Korea) and BSP-Luc (obtained from J.T. Kho, Chonnam National University, Korea) luciferase reporters contained the regulatory sequence of the osteoblast differentiation markers, ALP or BSP. The cells were transfected with a CMV promoter-driven $\beta$-galactosidase reporter (pCMV- $\beta$-gal), luciferase reporter and the indicated combinations of the expression plasmids. Thirty-six hours later, luciferase activities were measured using the Luciferase Reporter Assay kit (E1501; Promega, Madison, WI, USA) and a luminometer, and normalized with the corresponding $\beta$-galactosidase activities for transfection efficiency. Experiments were performed in triplicate and repeated at least 3 times. The averages and standard deviations (SD) of representative experiments are shown.

RNA preparation and semi-quantitative $R T-P C R$. Total cellular RNA was prepared using TRIzol reagent (Life Technologies) according to the manufacturer's instructions. Random hexamer-primed cDNA was synthesized from $1 \mu \mathrm{g}$ of total RNA using the SuperScript III First-Strand Synthesis System (Life Technologies). The following conditions were used for the amplification by PCR: initial denaturation at $94^{\circ} \mathrm{C}$ for $1 \mathrm{~min}$; followed by $23-30$ cycles of denaturation at $94^{\circ} \mathrm{C}$ for $30 \mathrm{sec}$, annealing at a temperature optimized for each primer pair for $30 \mathrm{sec}$, and extension at $72^{\circ} \mathrm{C}$ for $30 \mathrm{sec}$; final extension at $72^{\circ} \mathrm{C}$ for $5 \mathrm{~min}$. The following PCR primers were used: $A L P$ forward, 5'-GGGTGGACTACCTCTTAGGTC-3' and reverse, 5'-ATGATGTCCGTGGTCAATCCTG-3' (30 cycles); BSP forward, 5'-CAGAAGTGGATGAAAACGAG-3' and reverse, 5'-CGGTGGCGAGGTGGTCCCAT-3' (25 cycles); COL1A1 forward, 5'-TCTCCACTCTTCTAGGTTCCT-3' and reverse, 5'-TTGGGTCATTTCCACATGC-3' (23 cycles); Runx2 forward, 5'-AGCAACAGCAACAGCAG-3' and reverse, 5'-GTAATCTGACTCTGTCCTTG-3' (35 cycles); Osterix forward, 5'-GGGTTAAGGGGAGCAAAGTCAGAT-3' and reverse, 5'-CTGGGGAAAGGAGGCACAAAGAAG-3' (35 cycles); GAPDH forward, 5'-ACCACAGTCCATGCCA TCAC-3' and reverse, 5'-TCCACCACCCTGTTGCTGTA-3' (25 cycles).

ALP staining and activity assay. The $\mathrm{C} 2 \mathrm{C} 12$ cells were treated with BMP4 (30 ng/ml) for 3 days, fixed in $4 \%$ para- formaldehyde for $15 \mathrm{~min}$ at room temperature, rinsed with phosphate-buffered saline (PBS), and stained with 5-bromo-4chloro-3-indolyl phosphate/nitro blue tetrazolium (BCIP/NBT) solution (Sigma-Aldrich) for $15 \mathrm{~min}$ at room temperature. For ALP assay, the cells were washed with PBS and lysed in $0.5 \%$ Triton X-100. ALP enzymatic activity was measured using the SensoLyte pNPP ALP assay kit (AnaSpec, Inc., Fremont, $\mathrm{CA}, \mathrm{USA}$ ) according to the manufacturer's instructions.

Alizarin Red S staining. The C2C12 cells in 24-well plates were transfected using the PEI-mediated method. The $\mathrm{C} 2 \mathrm{C} 12$ cells were stimulated with BMP4. The cells were pre-treated with BMP4 for 10 days. These cells were cultured at $5 \% \mathrm{CO}_{2}, 37^{\circ} \mathrm{C}$. The transfected $\mathrm{C} 2 \mathrm{C} 12$ cells were then fixed in $4 \%$ paraformaldehyde for $15 \mathrm{~min}$ at room temperature and washed with PBS. They were then exposed to Alizarin Red S solution (no. A5533; Sigma-Aldrich) adjusted to $\mathrm{pH} 4.1-4.3$ using 0.5\% ammonium hydroxide for $30 \mathrm{~min}$ at room temperature. The mineralizationpositive cells were stained red.

Statistical analysis. All experiments were performed with triplicate independent samples and were repeated at least 3 times yielding qualitatively identical results. The results are expressed as the means \pm standard error of the mean. Data were analyzed using the Student's t-test (SPSS version 17.0 software; SPSS, Inc., Chicago, IL, USA). A value of $\mathrm{p}<0.05$ was considered to indicate a statistically significant difference.

\section{Results}

LES enhances osteoblast differentiation induced by BMP4. Recently, it was reported that LES regulates osteoclastogenesis in vitro (39). However, the signaling mechanisms of LES are less well known in osteoblastogenesis. The precise molecular signaling mechanisms of action of LES as regards osteoblast differentiation are not yet fully understood. Therefore, in this study, we examined the effects of LES on the osteoblast differentiation of $\mathrm{C} 2 \mathrm{C} 12$ cells. We examined whether LES affects BMP4-induced osteoblast differentiation. Stimulation with BMP4 induced the osteoblast differentiation of the $\mathrm{C} 2 \mathrm{C} 12$ myoblasts. The $\mathrm{C} 2 \mathrm{C} 12$ cells were cultured and treated with low and high concentrations ( 30 or $60 \mu \mathrm{g} / \mathrm{ml}$ ) of LES for 3 days. LES increased the expression of ALP, an osteoblast marker, in the cells stimulated with BMP4, as shown by ALP staining (Fig. 1A, top panel), and also increased ALP activity (Fig. 1B). Similarly, LES increased mineralization, as observed by Alizarin Red S staining (Fig. 1A, bottom panel). These results suggest that LES enhances osteoblast differentiation induced by BMP4.

LES affects the expression levels and transcriptional activity of osteoblast markers in BMP4-induced osteoblast differentiation. Previous studies have demonstrated that BMP4 gene transfer into rodent muscle promotes bone formation (40-43). In this study, we confirmed that LES enhances BMP4-induced osteoblast differentiation (Fig. 1). Treatment with LES increased the expression levels of the osteoblast transcription factors, Runx2, Osterix and Dlx5 (Fig. 2A), and those of the specific markers, $A L P, B S P$ and COL1A1, in the cells also treated with BMP4 (Fig. 2B). Moreover, we examined whether LES can modulate the transcriptional activity using the 


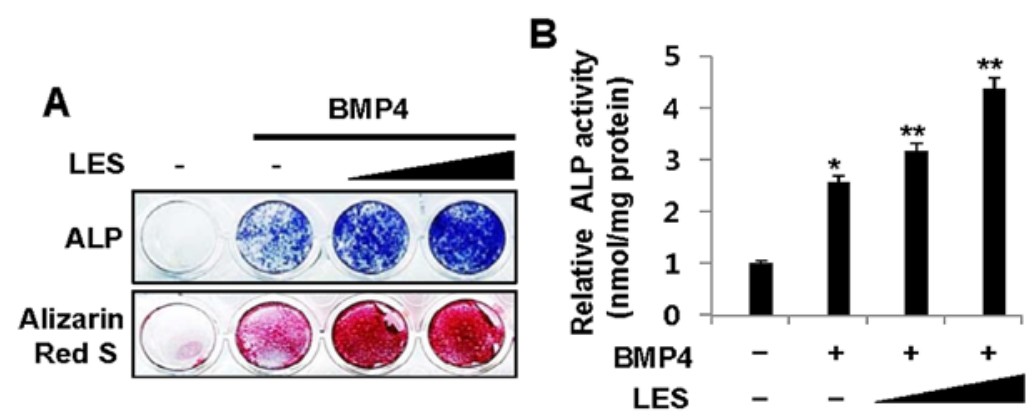

Figure 1. LES promotes bone morphogenetic protein 4 (BMP4)-induced osteoblast differentiation. C2C12 myoblasts were treated with BMP4 (30 ng/ml) and LES (each 30 or $60 \mu \mathrm{g} / \mathrm{ml}$ for A and B) for 3 days for alkaline phosphatase (ALP) staining, and for 14 days for (Alizarin Red S staining). (A) Osteoblast differentiation and mineralization evaluated by ALP staining and Alizarin Red S staining. The ALP-positive cells were stained blue/purple. (B) ALP activity was measured by ALP assay. "p $<0.05$ compared to the BMP4-untreated cells; ${ }^{* *} \mathrm{p}<0.05$ compared to the BMP4-treated cells not transfected with DNA. All experiments were repeated at least 3 times. The averages and standard deviations (SD) of representative experiments are shown. LES, ethanol (EtOH) extract from Lithospermum erythrorhizon Sieb. et Zucc.
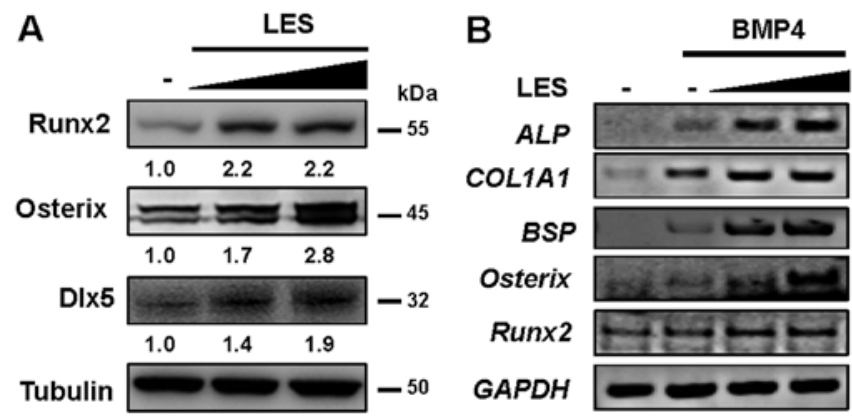

Figure 2. LES increases the expression of osteoblast target genes during osteoblast differentiation. $\mathrm{C} 2 \mathrm{C} 12$ cells were treated with bone morphogenetic protein 4 (BMP4) $(30 \mathrm{ng} / \mathrm{ml}$ ) and increasing amounts of LES (30 or $60 \mu \mathrm{g} / \mathrm{ml}$ ) for 3 days. (A) The endogenous expression levels of osteoblast target genes (Runx2, Osterix and Dlx5) in cell lysates compared by immunoblotting using antibody against Runx2, Osterix or Dlx5, respectively. Tubulin was used as a loading control. (B) The expression levels of the osteoblast-specific markers, alkaline phosphatase (ALP), bone sialoprotein (BSP), collagen type I, $\alpha 1$ (COL1AI), Osterix, Runx2 compared by RT-PCR. GAPDH was used as a loading control. LES, ethanol (EtOH) extract from Lithospermum erythrorhizon Sieb. et Zucc.
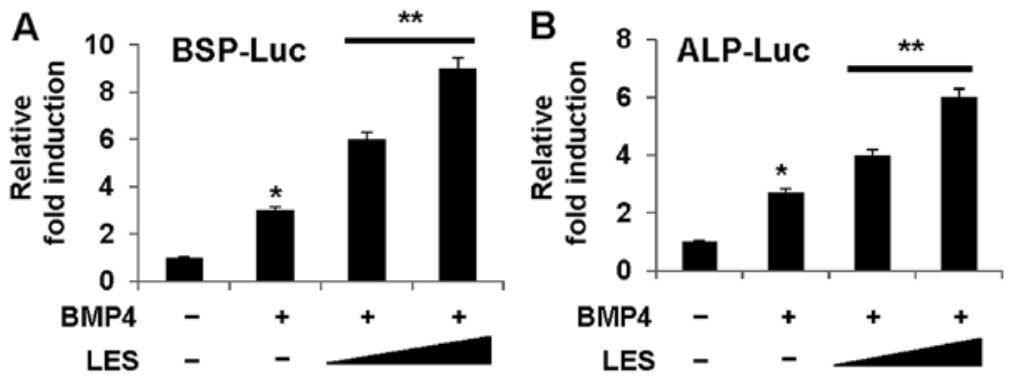

Figure 3. LES enhances the transcriptional activity of osteoblast markers during osteoblast differentiation. $\mathrm{C} 2 \mathrm{C} 12$ cells stimulated with bone morphogenetic protein 4 (BMP4) were transfected with CMV promoter-driven $\beta$-galactosidase reporter (pCMV- $\beta$-gal) $(0.05 \mu \mathrm{g})$, and with (A) a luciferase reporter bone sialoprotein (BSP)-Luc or (B) alkaline phosphatase (ALP)-Luc $(0.2 \mu \mathrm{g})$, and treated with increasing amounts of LES (30 or $60 \mu \mathrm{g} / \mathrm{ml})$. Luciferase activity was measured. "p $<0.05$ compared to cells not treated with BMP4; ${ }^{* *}$ p $<0.05$ compared to BMP4-treated cells and not transfected with any DNA plasmid. All experiments were repeated at least 3 times. The averages and standard deviations (SD) of representative experiments are shown. LES, ethanol (EtOH) extract from Lithospermum erythrorhizon Sieb. et Zucc.

osteoblast-specific luciferase reporters, BSP-Luc (Fig. 3A) and ALP-Luc (Fig. 3B). LES significantly enhanced the expression of the reporters. These results indicate that LES regulates the transcriptional activity of osteoblast transcription factors and is critical for the osteoblast transcription factor-induced expression, of at least a subset of osteoblast markers.

LES regulates the functions of the osteoblast-specific transcription factor, Runx2, in BMP4-induced osteoblast differentiation. The runt-related transcription factor, Runx2, regulates the expression of bone and cartilage-related genes and is required for bone formation. The regulatory mechanisms control both the activation and repression of Runx 2 gene transcription during osteoblast differentiation and skeletal development. Runx 2 is essential for the proper execution of the osteogenic program $(7,19,44)$. In this study, in order to elucidate the mechanisms of action of the major transcription factor, Runx2, in cells treated with LES, we examined whether 

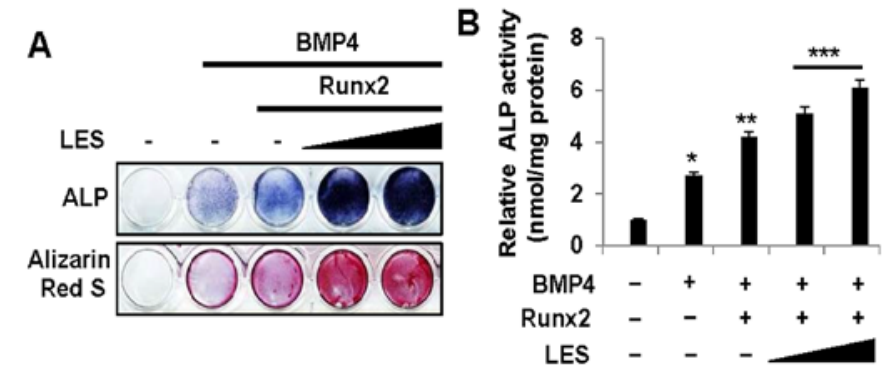

Figure 4. LES promotes osteoblast differentiation through Runx 2 activation. C2C12 cells were transfected with Myc-Runx2 $(1 \mu \mathrm{g})$ and then stimulated with bone morphogenetic protein 4 (BMP4) $(30 \mathrm{ng} / \mathrm{ml})$ or increasing amounts of LES (30 or $60 \mu \mathrm{g} / \mathrm{ml})$. (A) The extent of osteoblast differentiation and mineralization was evaluated by alkaline phosphatase (ALP) staining (at 3 days) or Alizarin Red S staining (at 14 days). (B) ALP activity was measured by ALP assay. ${ }^{*} p<0.05$ compared to BMP4-untreated cells; ${ }^{* *} \mathrm{p}<0.05$ compared to BMP4-treated cells not transfected with any DNA plasmid; ${ }^{* * *} \mathrm{p}<0.05$ compared to cells transfected with Runx2 expression plasmid and not treated with LES. All experiments were repeated at least 3 times. The averages and standard deviations (SD) of representative experiments are shown. LES, ethanol (EtOH) extract from Lithospermum erythrorhizon Sieb. et Zucc.
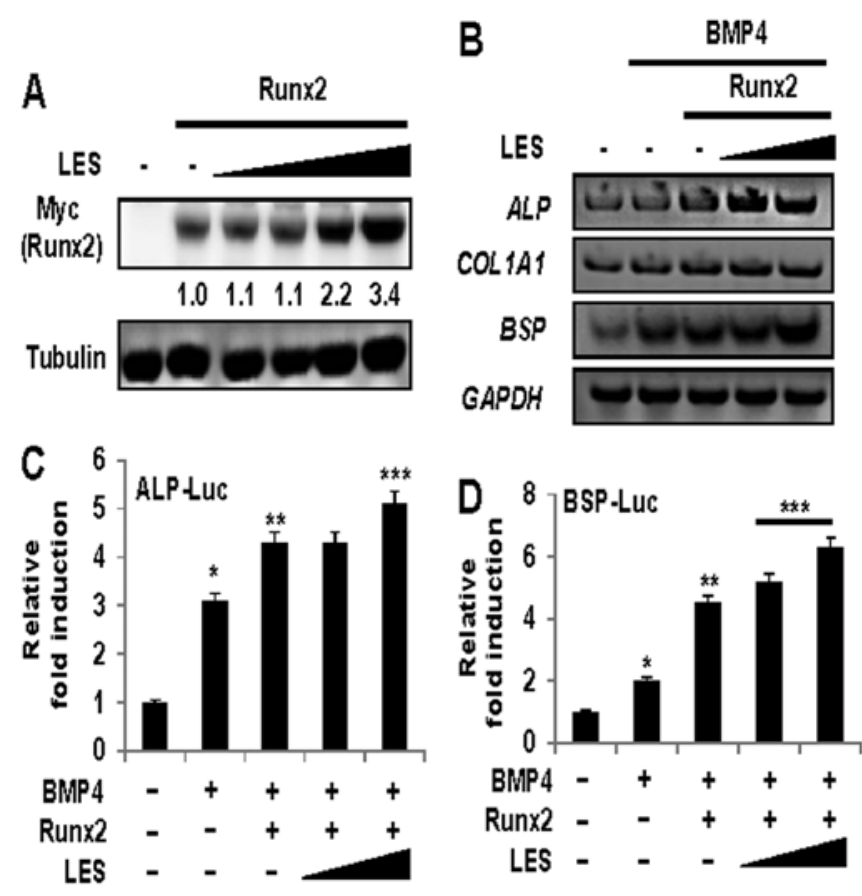

Figure 5. LES promotes osteoblast differentiation induced by bone morphogenetic protein 4 (BMP4) by ncreasing the expression and transcriptional activity of Runx2. (A) Cells (293) were transfected with Myc-Runx2 (1 $\mu \mathrm{g})$ and then treated with increasing amounts of LES $(5,15,30$ and $60 \mu \mathrm{g} / \mathrm{ml})$. The levels of overexpressed Runx2 were compared by immunoblotting using anti-Myc. Tubulin was used as a loading control. (B) The expression levels of the osteoblast-specific markers, alkaline phosphatase $(A L P)$, bone sialoprotein $(B S P)$ and collagen type I, $\alpha 1(C O L 1 A 1)$, were compared by RT-PCR. GAPDH was used as a loading control. (C and D) C2C12 cells were transfected with CMV promoter-driven $\beta$-galactosidase reporter (pCMV- $\beta$-gal) $(0.05 \mu \mathrm{g})$, Myc-tagged Runx2 ( $0.5 \mu \mathrm{g})$, and with luciferase reporter (C) ALP-Luc or (D) BSP-Luc $(0.2 \mu \mathrm{g})$ and treated with increasing amounts of LES (30 or $60 \mu \mathrm{g} / \mathrm{ml})$. Luciferase activity was measured. ${ }^{*} \mathrm{p}<0.05$ compared to BMP4-untreated cells; ${ }^{* *} \mathrm{p}<0.05$ compared to BMP4-treated cells not transfected with any DNA plasmid; ${ }^{* * *} \mathrm{p}<0.05$ compared to cells transfected with Runx2 expression plasmid and not treated with LES. The averages and standard deviations (SD) of representative experiments are shown. LES, ethanol (EtOH) extract from Lithospermum erythrorhizon Sieb. et Zucc.

LES affects Runx2 in cells stimulated with BMP4 to induce osteoblast differentiation. The cells stimulated with BMP and treated with LES were transfected with a Runx2 expression plasmid. First, we found that LES increased ALP activity, as shown by ALP staining (Fig. 4A, top panel), and also increased ALP activity (Fig. 4B) in the cells overexpressing Runx2 in the presence of BMP4. Similarly, LES increased mineralization, as shown by Alizarin Red S staining (Fig. 4A, bottom panel). We then investigated whether LES affects the protein level of Runx2. The protein levels of Runx2 were increased in the cells treated with LES (Fig. 5A). In addition, LES increased the expression of osteoblast specific markers in the cells stimulated with BMP4 (Fig. 2B). We then examined the effects of LES on the BMP4- and Runx2-induced expression of osteoblast marker genes (ALP, BSP and COL1A1). As shown in Fig. 5B, not only $A L P$ and $C O L 1 A 1$, the early-stage osteogenic differentiation markers, but also $B S P$, a late-stage osteogenic differentiation marker, was positively affected by LES. The expression of osteoblast markers in the cells stimulated with BMP4 to induce osteoblast differentiation was increased in the presence of Runx2 and LES. Finally, to examine whether LES can modulate the transcriptional activity of Runx2, we examined the effects of LES on the transcriptional activity of Runx 2 using the osteoblast-specific luciferase reporters, 

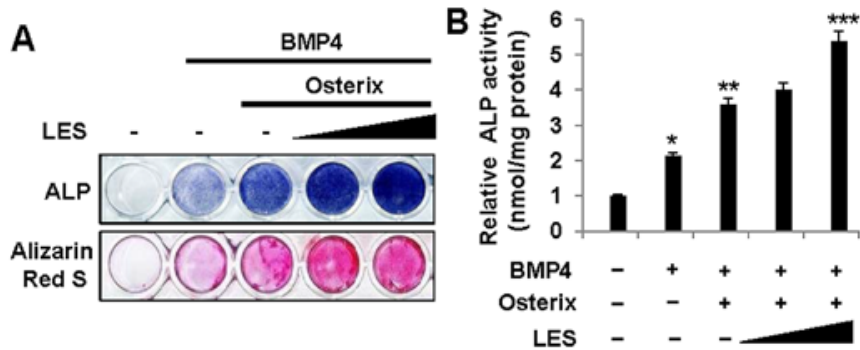

Figure 6. LES promotes osteoblast differentiation through Osterix activation. $\mathrm{C} 2 \mathrm{C} 12$ cells were transfected with Myc-Osterix $(0.5 \mu \mathrm{g})$ and then treated with bone morphogenetic protein 4 (BMP4) (30 ng/ml) or increasing amounts of LES (30 or $60 \mu \mathrm{g} / \mathrm{ml})$. (A) The extent of osteoblast differentiation and mineralization was evaluated by alkaline phosphatase (ALP) staining (at 3 days) or Alizarin Red S staining (at 14 days). (B) ALP activity was measured by ALP assay. " $p<0.05$ compared to BMP4-untreated cells; ${ }^{* *} \mathrm{p}<0.05$ compared to BMP4-treated cells not transfected with any DNA plasmid; ${ }^{* * *} \mathrm{p}<0.05$ compared to cells transfected wtih Osterix expression plasmid and not treated with LES. All experiments were repeated at least 3 times. The averages and standard deviations (SD) of representative experiments are shown. LES, ethanol (EtOH) extract from Lithospermum erythrorhizon Sieb. et Zucc.
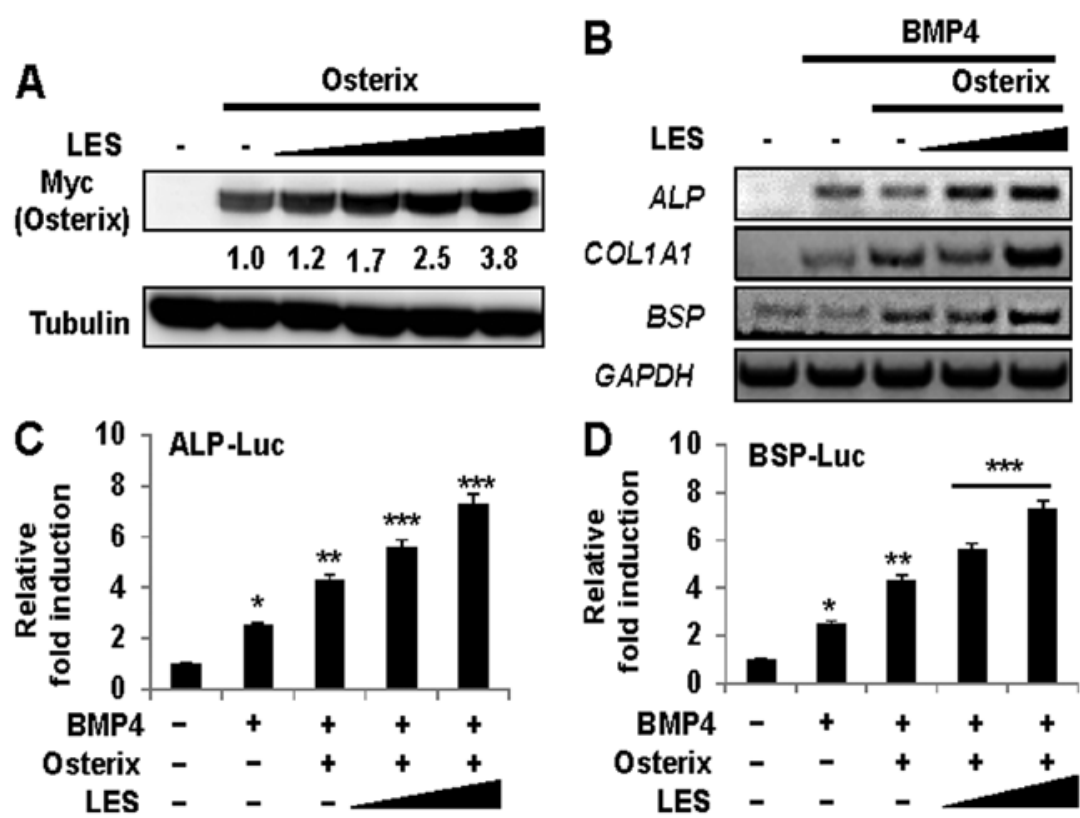

Figure 7. The expression and transcriptional activity of Osterix is markedly increased by LES during osteoblast differentiation. (A) Cells (293) were transfected with Myc-Osterix $(0.5 \mu \mathrm{g})$ and then treated with increasing amounts of LES $(5,15,30$ and $60 \mu \mathrm{g} / \mathrm{ml})$. The levels of overexpressed Osterix were compared by immunoblotting using anti-Myc. Tubulin was used as a loading control. (B) The expression levels of the osteoblast-specific markers, alkaline phosphatase ( $A L P$ ), bone sialoprotein $(B S P)$ and collagen type I, $\alpha 1$ (COL1A1), were compared by RT-PCR. GAPDH was used as a loading control. (C and D) $\mathrm{C} 2 \mathrm{C} 12$ cells were transfected with CMV promoter-driven $\beta$-galactosidase reporter (pCMV- $\beta$-gal) $(0.05 \mu \mathrm{g})$, Myc-tagged Osterix $(0.5 \mu \mathrm{g})$, and with luciferase reporter (C) ALP-Luc or (D) BSP-Luc $(0.2 \mu \mathrm{g})$ and treated increasing amounts of LES (30 or $60 \mu \mathrm{g} / \mathrm{ml})$. Luciferase activity was measured. "p $<0.05$ compared to BMP4-untreated cells; *** $<<0.05$ compared to BMP4-treated cells not transfected with any DNA plasmid; ${ }^{* * *} \mathrm{p}<0.05$ compared to cells transfected with Osterix expression plasmid and not treated with LEs. All experiments were repeated at least 3 times. The averages and standard deviations (SD) of representative experiments are shown. LES, ethanol (EtOH) extract from Lithospermum erythrorhizon Sieb. et Zucc.

ALP-Luc (Fig. 5C) and BSP-Luc (Fig. 5D). LES significantly enhanced the transcriptional activity of the Runx2-induced expression of the reporters. Taken together, these results suggest that LES regulates the expression levels and transcriptional activity of Runx2 during osteoblast differentiation.

LES regulates the functions of the osteoblast-specific transcription factor, Osterix, in BMP4-induced osteoblast differentiation. Osterix has been identified as a zinc fingercontaining transcription factor. It is required for osteoblast differentiation and bone formation (15). BMP4 induces osteoblast differentiation and promotes bone formation (40-43). In the present study, we examined whether LES affects the BMP4-induced osteoblast differentiation of $\mathrm{C} 2 \mathrm{C} 12$ cells.
Osteoblast differentiation and mineralization were measured by ALP staining and Alizarin Red S. LES increased ALP activity, as shown by ALP staining (Fig. 6A, top panel) and increased ALP activity (Fig. 6B) in the presence of Osterix and BMP4. Similarly, LES increased mineralization, as shown by Alizarin Red S staining (Fig. 6A, bottom panel). We also examined whether LES regulates the level of ectopically expressed Osterix protein in non-osteogenic 293 cells. LES significantly enhanced the level of overexpressed Osterix protein in a dose-dependent manner (Fig. 7A). In addition, we examined whether LES affects the transcriptional activity of Osterix using the osteoblast-specific luciferase reporters, ALP-Luc (Fig. 7C) and BSP-Luc (Fig. 7D). LES significantly enhanced the transcriptional activity of the Osterix-induced 
expression of the reporters. LES increased the expression of the osteoblast-specific marker genes $A L P, B S P$, and COL1A1, in the cells stimulated with BMP4 (Fig. 7B). Taken together, these results suggest that LES regulates the expression levels and transcriptional activity of Osterix during osteoblast differentiation.

\section{Discussion}

In this study, we examined the effects of LES, as a novel osteogenic material, on osteoblast differentiation. In previous studies, shikonin, from the root of Lithospermum erythrorhizon, has been shown to protect cartilage in rheumatoid arthritis, but also to induce osteoclastogenesis in vitro $(38,39)$. However, hydrophobic shikonin and its derivatives are not extracted in the water-soluble EtOH extract, LES.

In our results, we found that LES promoted osteoblast differentiation and increased the expression levels and transcriptional activity of Runx 2 and Osterix, the master genes of osteoblast differentiation. Even though the functions of LES in osteoblastogenesis are not yet well understood, our results indicate that the water-soluble components of LR could be the main active components which enhance osteoblastogenesis, instead of shikonin and its derivative. In other studies, lithospermic acid, a water-soluble phenolic compound, which is a standardized major bioactive component at a concentration of $2 \mathrm{mg} / \mathrm{g} \mathrm{(45),}$ and polysaccharides such as lithospermans A, B and C (46) have also been identified in the EtOH extracts of LR. Therefore, a strong osteoblast differentiation effect by LES may be induced directly or indirectly by lithospermic acid and lithospermans A, B and C. However, further studies are required in order to evaluate the effects of the hydrophilic compounds from LES on osteoblastogenesis. Lithospermic acid is known to have antioxidant activity (47) and hypouricemic activity, and to exert anti-inflammatory effects (48), and anti-diabetic effects (49). However, there has been no study to date on the effects of lithospermic acid on osteoblast differentiation, at least to the best of our knowledge. In other studies, the $95 \% \mathrm{EtOH}$ extract of LR was shown to exert a moisturizing effect (50) and the $70 \% \mathrm{EtOH}$ extract of LR enhanced the epidermal level of ceramides (51).

The specific master gene of osteoblast differentiation, Runx2, plays a key role in bone formation. A loss-of-function mutation of Runx 2 in mice results in no mineralized bone and the lack of mature osteoblasts and osteogenic differentiation markers $(12,52,53)$. The function of Runx2 is regulated at several levels, such as transcription, translation, post-translational modification and protein-protein interactions by multiple signal transduction pathways. It is known that various kinases phosphorylate Runx2. The phosphorylation of Runx2 is an important mechanism that regulates its activity during osteoblastogenesis. Bone formation is stimulated by the phosphorylation of Runx 2 via the MAPK/ERK signaling pathway $(54,55)$ or protein kinase $C(P K C)-\delta(56)$. Thus, the regulation of Runx 2 activity by the alteration of its phosphorylation status is important in bone formation.

Osterix is a novel zinc finger-containing transcription factor that is essential for the differentiation of pre-osteoblasts into functional osteoblasts (15). The function of Osterix can be regulated via post-translational modification by protein kinase-mediated osteogenesis. In a previous study, p38 was shown to regulate the expression of osteoblast-specific genes by the phosphorylation of Osterix (57). It has also been suggested that Akt induces the phosphorylation of threonine residue(s) on Osterix during osteoblast differentiation (58). Tyrosine kinase Src enhances osteogenic differentiation through the phosphorylation of Osterix (59).

Previous studies have revealed that shikonin, a major component of LES is involved in the regulation of ERK1/2 and Akt phosphorylation $(60,61)$. Therefore, studies determining the phosphorylation by several protein kinases are warranted in order to understand the significance of the regulation of LES and the osteoblast-specific master genes, Runx2 and Osterix. The identification of protein kinase mechanisms underlying the effects of LES on osteoblast differentiation will enhance our understanding of the regulatory mechanisms of Osterix and Runx 2 osteogenic function. Our study provides a basis for understanding the effects of LES on osteoblast differentiation.

In conclusion, in this study, we demonstrate that LES enhances osteoblast differentiation. LES modulates the function of the master genes, Runx 2 and Osterix, through the regulation of their protein expression and transcriptional activity. Thus, LES may be a potential therapeutic agent for bone diseases, including osteoporosis. In addition, LR has been approved as a food source by the Ministry of Food and Drug safety, South Korea (MFDS), and the EtOH extract of LR (LES) is recognized as a safe food material for humans. Our data indicate that LES has potential for development as a potential candidate material for health functional food for bone health.

\section{Acknowledgements}

This study was supported by a grant from the Cooperative Research Program for Agriculture Science and Technology Development, Rural Development Administration, Republic of Korea (project no. PJ01122302).

\section{References}

1. Katagiri $\mathrm{T}$ and Takahashi $\mathrm{N}$ : Regulatory mechanisms of osteoblast and osteoclast differentiation. Oral Dis 8: 147-159, 2002.

2. Heino TJ and Hentunen TA: Differentiation of osteoblasts and osteocytes from mesenchymal stem cells. Curr Stem Cell Res Ther 3: 131-145, 2008.

3. Teitelbaum SL: Bone remodeling and the osteoclast. J Bone Miner Res 8 (Suppl 2): S523-S525, 1993.

4. Kawamura N, Kugimiya F, Oshima Y, Ohba S, Ikeda T, Saito T, Shinoda Y, Kawasaki Y, Ogata N, Hoshi K, et al: Akt1 in osteoblasts and osteoclasts controls bone remodeling. PLoS One 2: e1058, 2007.

5. Blum B, Moseley J, Miller L, Richelsoph K and Haggard W: Measurement of bone morphogenetic proteins and other growth factors in demineralized bone matrix. Orthopedics 27 (Suppl 1): s161-s165, 2004.

6. Yamaguchi A, Komori T and Suda T: Regulation of osteoblast differentiation mediated by bone morphogenetic proteins, hedgehogs, and Cbfa1. Endocr Rev 21: 393-411, 2000.

7. Ohba S, Chung UI and Tei Y: Osteoblast differentiation induced by BMP signaling and Runx 2 through $\mathrm{Cbfb}$ regulation. Nihon Rinsho 65 (Suppl 9): 71-74, 2007 (In Japanese).

8. Matsubara T, Kida K, Yamaguchi A, Hata K, Ichida F, Meguro H, Aburatani H, Nishimura R and Yoneda T: BMP2 regulates Osterix through Msx 2 and Runx 2 during osteoblast differentiation. J Biol Chem 283: 29119-29125, 2008.

9. Ulsamer A, Ortuño MJ, Ruiz S, Susperregui AR, Osses N, Rosa JL and Ventura F: BMP-2 induces Osterix expression through up-regulation of Dlx 5 and its phosphorylation by $\mathrm{p} 38$. J Biol Chem 283: 3816-3826, 2008. 
10. Komori T: Regulation of osteoblast differentiation by transcription factors. J Cell Biochem 99: 1233-1239, 2006.

11. Lee MH, Kwon TG, Park HS, Wozney JM and Ryoo HM BMP-2-induced Osterix expression is mediated by Dlx5 but is independent of Runx2. Biochem Biophys Res Commun 309: 689-694, 2003

12. Komori T, Yagi H, Nomura S, Yamaguchi A, Sasaki K, Deguchi K, Shimizu Y, Bronson RT, Gao YH, Inada M, et al: Targeted disruption of Cbfa1 results in a complete lack of bone formation owing to maturational arrest of osteoblasts. Cell 89: 755-764, 1997.

13. Bendall AJ and Abate-Shen C: Roles for Msx and Dlx homeoproteins in vertebrate development. Gene 247: 17-31, 2000.

14. Hassan MQ, Javed A, Morasso MI, Karlin J, Montecino M, van Wijnen AJ, Stein GS, Stein JL and Lian JB: Dlx3 transcriptional regulation of osteoblast differentiation: temporal recruitment of Msx2, Dlx3, and Dlx5 homeodomain proteins to chromatin of the osteocalcin gene. Mol Cell Biol 24: 9248-9261, 2004

15. Nakashima K, Zhou X, Kunkel G, Zhang Z, Deng JM, Behringer RR and de Crombrugghe $B$ : The novel zinc finger-containing transcription factor osterix is required for osteoblast differentiation and bone formation. Cell 108: 17-29, 2002.

16. Li H, Marijanovic I, Kronenberg MS, Erceg I, Stover ML, Velonis D, Mina M, Heinrich JG, Harris SE, Upholt WB, et al: Expression and function of Dlx genes in the osteoblast lineage. Dev Biol 316: 458-470, 2008.

17. Komori T: Regulation of skeletal development by the Runx family of transcription factors. J Cell Biochem 95: 445-453, 2005.

18. Cheng A and Genever PG: SOX9 determines RUNX2 transactivity by directing intracellular degradation. J Bone Miner Res 25: 2680-2689, 2010.

19. Stein GS, Lian JB, van Wijnen AJ, Stein JL, Montecino M, Javed A, Zaidi SK, Young DW, Choi JY and Pockwinse SM: Runx 2 control of organization, assembly and activity of the regulatory machinery for skeletal gene expression. Oncogene 23 : 4315-4329, 2004.

20. Lee KS, Kim HJ, Li QL, Chi XZ, Ueta C, Komori T, Wozney JM, Kim EG, Choi JY, Ryoo HM and Bae SC: Runx2 is a common target of transforming growth factor beta1 and bone morphogenetic protein 2, and cooperation between Runx2 and Smad5 induces osteoblast-specific gene expression in the pluripotent mesenchymal precursor cell line C2C12. Mol Cell Biol 20: 8783-8792, 2000.

21. Mukherjee A and Rotwein P: Akt promotes BMP2-mediated osteoblast differentiation and bone development. J Cell Sci 122: 716-726, 2009

22. Phimphilai M, Zhao Z, Boules $\mathrm{H}$, Roca $\mathrm{H}$ and Franceschi RT: BMP signaling is required for RUNX2-dependent induction of the osteoblast phenotype. J Bone Miner Res 21: 637-646, 2006.

23. Javed A, Afzal F, Bae JS, Gutierrez S, Zaidi K, Pratap J, van Wijnen AJ, Stein JL, Stein GS and Lian JB: Specific residues of RUNX2 are obligatory for formation of BMP2-induced RUNX2-SMAD complex to promote osteoblast differentiation. Cells Tissues Organs 189: 133-137, 2009.

24. Fu H, Doll B, McNelis T and Hollinger JO: Osteoblast differentiation in vitro and in vivo promoted by Osterix. J Biomed Mater Res A 83: 770-778, 2007.

25. Tu Q, Valverde P and Chen J: Osterix enhances proliferation and osteogenic potential of bone marrow stromal cells. Biochem Biophys Res Commun 341: 1257-1265, 2006.

26. Kim YJ, Kim HN, Park EK, Lee BH, Ryoo HM, Kim SY, Kim IS, Stein JL, Lian JB, Stein GS, et al: The bone-related $\mathrm{Zn}$ finger transcription factor Osterix promotes proliferation of mesenchymal cells. Gene 366: 145-151, 2006.

27. Hatta M, Yoshimura Y, Deyama Y, Fukamizu A and Suzuki K Molecular characterization of the zinc finger transcription factor, Osterix. Int J Mol Med 17: 425-430, 2006.

28. Zhang C, Cho K, Huang Y, Lyons JP, Zhou X, Sinha K, McCrea PD and de Crombrugghe B: Inhibition of Wnt signaling by the osteoblast-specific transcription factor Osterix. Proc Nat Acad Sci USA 105: 6936-6941, 2008.

29. New SA, Robins SP, Campbell MK, Martin JC, Garton MJ, Bolton-Smith C, Grubb DA, Lee SJ and Reid DM: Dietary influences on bone mass and bone metabolism: further evidence of a positive link between fruit and vegetable consumption and bone health? Am J Clin Nutr 71: 142-151, 2000.

30. Tucker KL, Hannan MT, Chen H, Cupples LA, Wilson PW and Kiel DP: Potassium, magnesium, and fruit and vegetable intakes are associated with greater bone mineral density in elderly men and women. Am J Clin Nutr 69: 727-736, 1999.
31. Chen X, Yang L, Zhang N, Turpin JA, Buckheit RW, Osterling C, Oppenheim JJ and Howard OM: Shikonin, a component of chinese herbal medicine, inhibits chemokine receptor function and suppresses human immunodeficiency virus type 1 . Antimicrob Agents Chemother 47: 2810-2816, 2003

32. Gao H, Liu L, Qu ZY, Wei FX, Wang SQ, Chen G, Qin L, Jiang FY, Wang YC, Shang L and Gao CY: Anti-adenovirus activities of shikonin, a component of Chinese herbal medicine in vitro. Biol Pharm Bull 34: 197-202, 2011.

33. Jin R, Wan LL, Mitsuishi T, Kodama K and Kurashige S: Immunomodulative effects of Chinese herbs in mice treated with anti-tumor agent cyclophosphamide. Yakugaku Zasshi 114: 533-538, 1994 (In Japanese).

34. Chen HM, Wang PH, Chen SS, Wen CC, Chen YH, Yang WC and Yang NS: Shikonin induces immunogenic cell death in tumor cells and enhances dendritic cell-based cancer vaccine. Cancer Immunol Immunother 61: 1989-2002, 2012.

35. Wang XC, Feng J, Huang F, Fan YS, Wang YY, Cao LY and Wen CP: Effects of shikonin isolated from zicao on lupus nephritis in NZB/W F1 mice. Biol Pharm Bull 32: 1565-1570, 2009.

36. Kim SJ, Kim JM, Shim SH and Chang HI: Shikonin induces cell cycle arrest in human gastric cancer (AGS) by early growth response 1 (Egr1)-mediated p21 gene expression. J Ethnopharmacol 151: 1064-1071, 2014.

37. Dai Q, Fang J and Zhang FS: Dual role of shikonin in early and late stages of collagen type II arthritis. Mol Biol Rep 36: $1597-1604,2009$.

38. Kim YO, Hong SJ and Yim SV: The efficacy of shikonin on cartilage protection in a mouse model of rheumatoid arthritis. Korean J Physiol Pharmacol 14: 199-204, 2010.

39. Youn YN, Lim E, Lee N, Kim YS, Koo MS and Choi SY: Screening of Korean medicinal plants for possible osteoclastogenesis effects in vitro. Genes Nutr 2: 375-380, 2008.

40. Kotajima S, Kishimoto KN, Watanuki M, Hatori M and Kokubun S: Gene expression analysis of ectopic bone formation induced by electroporatic gene transfer of BMP4. Ups J Med Sci 111: 231-241, 2006.

41. Li G, Peng H, Corsi K, Usas A, Olshanski A and Huard J: Differential effect of BMP4 on NIH/3T3 and C2C12 cells: implications for endochondral bone formation. J Bone Miner Res 20: 1611-1623, 2005.

42. Ou M, Zhao Y, Zhang F and Huang X: Bmp2 and Bmp4 accelerate alveolar bone development. Connect Tissue Res 56: 204-211, 2015.

43. Zhang Z, Song $\mathrm{Y}$, Zhang $\mathrm{X}$, Tang J, Chen $\mathrm{J}$ and Chen $\mathrm{Y}$ : Msx1/Bmp4 genetic pathway regulates mammalian alveolar bone formation via induction of Dlx 5 and Cbfa1. Mech Dev 120: 1469-1479, 2003.

44. Drissi H, Luc Q, Shakoori R, Chuva De Sousa Lopes S, Choi JY, Terry A, Hu M, Jones S, Neil JC, Lian JB, et al: Transcriptional autoregulation of the bone related CBFA1/RUNX2 gene. J Cell Physiol 184: 341-350, 2000.

45. Thuong PT, Kang KW, Kim JK, Seo DB, Lee SJ, Kim SH and Oh WK: Lithospermic acid derivatives from Lithospermum erythrorhizon increased expression of serine palmitoyltransferase in human HaCaT cells. Bioorg Med Chem Lett 19: 1815-1817, 2009

46. Konno $\mathrm{C}$, Mizuno $\mathrm{T}$ and Hikino $\mathrm{H}$ : Isolation and hypoglycemic activity of lithospermans A, B and C, glycans of Lithospermum erythrorhizon roots. Planta Med 51: 157-158, 1985.

47. Jin CJ, Yu SH, Wang XM, Woo SJ, Park HJ, Lee HC, Choi SH, Kim KM, Kim JH, Park KS, et al: The effect of lithospermic acid, an antioxidant, on development of diabetic retinopathy in spontaneously obese diabetic rats. PLoS One 9: e98232, 2014.

48. Liu X, Chen R, Shang Y, Jiao B and Huang C: Lithospermic acid as a novel xanthine oxidase inhibitor has anti-inflammatory and hypouricemic effects in rats. Chem Biol Interact 176: 137-142, 2008.

49. Kang ES, Lee GT, Kim BS, Kim CH, Seo GH, Han SJ, Hur KY, Ahn CW, Ha H, Jung M, et al: Lithospermic acid B ameliorates the development of diabetic nephropathy in OLETF rats. Eur J Pharmacol 579: 418-425, 2008.

50. Chang MJ, Huang HC, Chang HC and Chang TM: Cosmetic formulations containing Lithospermum erythrorhizon root extract show moisturizing effects on human skin. Arch Dermatol Res 300: 317-323, 2008

51. Kim J and Cho Y: Gromwell (Lithospermum erythrorhizon) supplementation enhances epidermal levels of ceramides, glucosylceramides, $\beta$-glucocerebrosidase, and acidic sphingomyelinase in NC/Nga mice. J Med Food 16: 927-933, 2013 
52. Mundlos S, Otto F, Mundlos C, Mulliken JB, Aylsworth AS, Albright S, Lindhout D, Cole WG, Henn W, Knoll JH, et al: Mutations involving the transcription factor CBFA1 cause cleidocranial dysplasia. Cell 89: 773-779, 1997.

53. Otto F, Thornell AP, Crompton T, Denzel A, Gilmour KC, Rosewell IR, Stamp GW, Beddington RS, Mundlos S, Olsen BR, et al: Cbfa1, a candidate gene for cleidocranial dysplasia syndrome, is essential for osteoblast differentiation and bone development. Cell 89: 765-771, 1997.

54. Qiao M, Shapiro P, Kumar R and Passaniti A: Insulin-like growth factor-1 regulates endogenous RUNX2 activity in endothelial cells through a phosphatidylinositol 3-kinase/ERK-dependent and Akt-independent signaling pathway. J Biol Chem 279: 42709-42718, 2004

55. Xiao G, Jiang D, Gopalakrishnan R and Franceschi RT: Fibroblast growth factor 2 induction of the osteocalcin gene requires MAPK activity and phosphorylation of the osteoblast transcription factor, Cbfa1/Runx2. J Biol Chem 277: 36181-36187, 2002.

56. Kim BG, Kim HJ, Park HJ, Kim YJ, Yoon WJ, Lee SJ, Ryoo HM and Cho JY: Runx2 phosphorylation induced by fibroblast growth factor-2/protein kinase C pathways. Proteomics 6: 1166-1174, 2006.
57. Ortuño MJ,Ruiz-Gaspà S, Rodríguez-CarballoE, Susperregui AR, Bartrons R, Rosa JL and Ventura F: p38 regulates expression of osteoblast-specific genes by phosphorylation of osterix. J Biol Chem 285: 31985-31994, 2010.

58. Choi YH, Jeong HM, Jin YH, Li H, Yeo CY and Lee KY: Akt phosphorylates and regulates the osteogenic activity of Osterix. Biochem Biophys Res Commun 411: 637-641, 2011.

59. Choi YH, Han Y, Lee SH, Cheong H, Chun KH, Yeo CY and Lee KY: Src enhances osteogenic differentiation through phosphorylation of Osterix. Mol Cell Endocrinol 407: 85-97, 2015.

60. Öberg AI, Yassin K, Csikasz RI, Dehvari N, Shabalina IG, Hutchinson DS, Wilcke M, Östenson CG and Bengtsson T: Shikonin increases glucose uptake in skeletal muscle cells and improves plasma glucose levels in diabetic Goto-Kakizaki rats. PLoS One 6: e22510, 2011.

61. Gwon SY, Ahn JY, Jung CH, Moon BK and Ha TY: Shikonin suppresses ERK 1/2 phosphorylation during the early stages of adipocyte differentiation in 3T3-L1 cells. BMC Complement Altern Med 13: 207, 2013. 